\title{
Decomposition of waste DNA with extended autoclaving under unsaturated steam
}

\author{
Tetsushi Suyama and Mamoru Kawaharasaki \\ National Institute of Advanced Industrial Science and Technology (AIST). Tsukuba, Ibaraki, Japan
}

BioTechniques 55:296-299 (December 2013) doi 10.2144/000114113

Keywords: PCR; autoclave; false-positive; contamination; DNA waste; decomposition

Carryover and false-positive amplification of undesired DNA sequences are serious problems in research and diagnostic testing using PCR. One possible source of DNA cross-contamination can be the autoclave if DNA contained in waste is not effectively decomposed and contaminates the autoclave. To assess this possibility, we used a 2682 bp PCR product as a model waste DNA and quantified the amplifiability of an 84 bp short fragment derived from the model waste DNA in the steam and the residual bottom water after autoclaving. Autoclaving under the standard conditions of $121^{\circ} \mathrm{C}$ for $20 \mathrm{~min}$ did not sufficiently remove amplifiability from the model DNA and was found to be a possible source of laboratory contamination. However, the amplifiable template was removed after autoclaving at $121^{\circ} \mathrm{C}$ for $80 \mathrm{~min}$. Fragmentation and hydrolysis may occur during autoclaving, and the presence of atmospheric oxygen facilitated the decomposition. These findings will help researchers develop better strategies for disposing of DNA waste.

For thermo-tolerant microorganisms, autoclaving with saturated steam (100\% steam containing no air) at $121^{\circ} \mathrm{C}$ for 15-20 min has been considered sufficient for sterilizing samples, reagents, growth media, plastic, and glass $(1,2)$. However, many reports indicate that the $121^{\circ} \mathrm{C}$ for $15-20$ min method is not suitable for inactivating PCR-amplifiable DNA in samples, reagents, plastic and glass (3-8). It has also been suggested that the aerosol derived from inactivated Staphylococcus cells can cause cross-contamination in the autoclave chamber (9). But there remain situations in which one cannot avoid autoclaving waste that contains genomic DNA, plasmids, PCR products, etc.

Here, we assess the possibility of DNA cross-contamination and leakage during autoclaving. A PCR product $(2682 \mathrm{bp}$, GC content $=50.6 \%$, amplified from a linearized pUC19 plasmid) was used as model waste DNA. A short, high-GC content fragment $(84 \mathrm{bp}, \mathrm{GC}$ content
$=61.9 \%)$ from that PCR product was quantified. Such fragments are known to be particularly difficult to remove $(3,4,7,10,11)$. It has been reported that uncapped processing with saturated steam at $121^{\circ} \mathrm{C}$ for $120-180 \mathrm{~min}$ prevents PCR amplification of DNA markers in dried saliva stains using forensic human genotyping kits (7). The fact that $120-180$ min autoclaving effectively removes the template activity of DNA means it is possible to operate an autoclave chamber for disposal of DNA waste, but leakage of contaminants must still be carefully avoided. Our study was designed to ascertain the effect of extended autoclaving on amplifiable template removal in laboratory waste, with a focus on preventing DNA contamination from the autoclave.

\section{Materials and methods}

A PCR product (2682 bp, GC content $=50.6 \%)$ was amplified from a HindIII digest of pUC19 plasmid, using ExTaq polymerase (Takara, Shiga, Japan) with forward (5'-TGGCGTAATCATGGTCATAGCTG) and reverse (5'-TGCATGCCTGCAGGTCGACTC) primers. The crude product was used in the following experiments.

The autoclave (Model KS-243; Tomy Seiko Co., Ltd. Tokyo, Japan) used in this study had the following features: 22 $\mathrm{L}$ in effective internal chamber volume, automatic displacement of chamber air by saturated steam before achieving $121^{\circ} \mathrm{C}$, and automatic control of chamber temperature and pressure by exhausting steam during heating and sterilization. The chamber was washed with a large volume of water before the experiment. Cleanliness was assessed by a blank test without loading DNA samples at the beginning and at the time of every other leak-test with loading of model waste DNA described below, as well as at the end of the series of experiments. Two liters of fresh water (deionized water, $15 \mathrm{M} \Omega \mathrm{cm}$,

\section{Method summary:}

Here we assess the possibility of DNA cross-contamination and leakage during autoclaving. A PCR product (2682 bp, GC content $=$ $50.6 \%$, amplified from a linearized pUC19 plasmid) was used as model waste DNA. A short, high-GC content fragment (84 bp, GC content $=61.9 \%$ ) from that PCR product was quantified in the steam and residual bottom water after autoclaving by using microfluidic digital PCR and real-time PCR. 
free of template DNA) were placed in the autoclave chamber, and the samples were placed at the center of the stainless steel basket. Autoclaving started at room temperature. All samples were collected from the chamber after cooling to $35^{\circ} \mathrm{C}$. The water at the bottom of the chamber (bottom water) was also collected through the drain after cooling down to $35^{\circ} \mathrm{C}$. For steam collection, the exhaust was collected from the exhaust hose in a 20 L heat-resistant plastic bag, chilled with crushed ice, during the steps of heating, sterilizing at $121^{\circ} \mathrm{C}$, and cooling to $100^{\circ} \mathrm{C}$.

The bottom water $(\sim 1.9 \mathrm{~L})$ and the water derived from steam $(\sim 100$ $\mathrm{mL}$ ) were condensed and bufferexchanged with TE (final volume 100 $\mu \mathrm{L}$ ) using Vivaspin 15R (VS15RH02) and Vivacon 500 (VN01H02) concentrators (Hydrosart 10,000 MWCO; Sartorius Stedim Biotech GmbH, Göttingen, Germany), which are capable of collecting DNA molecules larger than $30 \mathrm{bp}$ at an efficiency of $94 \%$ (www. sartorius.com). Samples for prolonged autoclaving (PCR product in TE buffer and water) were also prepared using the Vivacon 500 concentrator.

The template copy number in the standard samples was counted by digitalPCR assay with three separate panels of a 12.765 Digital Array (Fluidigm, South San Francisco, CA,) for each sample. Sample copy number was determined before and after processing by duplicate real-time PCR assays in reference to standard samples using a $7900 \mathrm{HT}$ Sequence Detection system (Applied Biosystems, Foster City, CA). A pair of primers (5'- CTGTCGTGCCAGCTGCATTA and 5'- GAGCGAGGAAGCGGAAGAG) and a TaqMan probe (5'FAM- ATCGGCCAACGCGCGGG-3' TAMRA; Applied Biosystems) were designed for detecting a short region ( $84 \mathrm{bp}, \mathrm{GC}$ content $=61.9 \%$ ) in the 2682 bp PCR product and were utilized for digital-PCR and real-time PCR assays. Data represent mean \pm SD of duplicate real-time PCR assays unless otherwise specified.

\section{Results and discussion}

The cross-contamination of DNA templates during autoclaving and leakage of the contaminant from the autoclave have been suspected but not verified by reliable evidence (9). We used model waste composed of a piece of wipe-paper, PCR tubes, pipette tips, and $400 \mu \mathrm{L}$ PCR product containing $(7.15 \pm 0.01) \times$ $10^{14}$ copies of the template (mimicking typical laboratory waste contaminated with PCR products) for assessing DNA contamination from the autoclave. The model waste was carefully placed in a 500 $\mathrm{mL}$ Pyrex beaker and then located at the center of the stainless steel basket in the autoclave chamber so that the waste was not in contact with the surroundings but was in contact with the atmospheric phase over the wall of the beaker with a height of $4 \mathrm{~cm}$.

After processing at $121^{\circ} \mathrm{C}$ for 20 min, $(2.12 \pm 0.42) \times 10^{6}$ copies amplifiable template (mean \pm SD for 4 separate autoclavings) were found in the bottom water. More than $1 / 10^{8}$ of the starting amount of model DNA molecules were considered to be discharged from the model waste and collected into the bottom water during autoclaving. Meanwhile, amplifiable template was not detected in the steam fractions after autoclaving the model waste. Since the lower limit of calibration for the real-time PCR assay was 8.10 copies $/ 1 \mu \mathrm{L}$ sample, the absence of amplification implies very little or no template in the steam (less than 810 copies in total), but it is obvious that the migration of template DNA from the model waste to the bottom water was mediated by the steam. Furthermore, steam fractions taken before cleaning the chamber were not free of pUC19 template, either. Therefore, steam may contain a trace amount of template DNA,

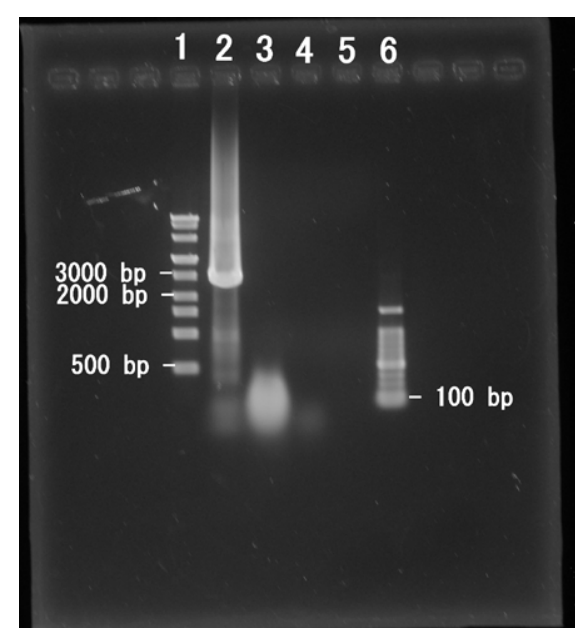

Figure 1. Fragmentation of DNA in samples autoclaved with encapsulation. All samples were diluted with equal amounts of TE after processing, and $3 \mu \mathrm{L}$ of each was loaded: the original sample of the 2682 bp PCR product (lane 2); samples processed at $121^{\circ} \mathrm{C}$ for $20 \mathrm{~min}$ (lane 3), $40 \mathrm{~min}$ (lane 4), and $120 \mathrm{~min}$ (lane 5). Novagen 0.5-12 kb Perfect DNA Markers (lane 1) (Merck KGaA, Darmstadt, Germany) and 100 bp DNA Ladder Markers (lane 6) (Takara) were loaded as references. The lowest markers in lanes 1 and 6 are $500 \mathrm{bp}$ and $100 \mathrm{bp}$, respectively. contaminating the exhaust system. We conclude that autoclaving is a source of contamination that could result in falsepositive PCR reactions. Thus, it would be better to dispose of DNA waste without autoclaving. However, as demonstrated by Gefrides, et al. (7), DNA is susceptible to extended processing by autoclaving. If the autoclave is utilized for decomposing DNA waste, contamination via exhaust steam has to be carefully avoided. For this reason, we endeavored to find an effective protocol for autoclaving DNA.

\section{Decomposition by encapsulation}

We examined whether contamination by leakage could be prevented when autoclaving encapsulated DNA samples. Ten microliters of a PCR product containing $(8.71 \pm 1.15) \times 10^{11}$ copies of the template DNA were encapsulated in a $2 \mathrm{~mL}$ polypropylene micro-tube with a screw-cap and an ethylene-propylene rubber O-ring (ASSIST Tube 72.694.100S, SARSTEDT, Tokyo, Japan). The initial amounts of the samples and evaporation during autoclaving were assessed gravimetrically at a precision of $0.01 \mathrm{mg}$. The micro-tube was supported by a cubic tube rack with a height of 9 cm (USA Scientific, Inc., Ocala, FL) and placed at the center of the stainless steel basket. Sample leakage was not observed during the autoclaving. Figure 1 shows an electropherogram for the autoclaved samples. The band at 2682 bp disappeared, and a smeared band at around $100 \mathrm{bp}$ was observed after $20 \mathrm{~min}$ and $40 \mathrm{~min}$ processing. The smeared band disappeared after $120 \mathrm{~min}$ of processing. PCR template activity was not observed in the $120 \mathrm{~min}$ processed sample, while it remained in the $20 \mathrm{~min}$ and $40 \mathrm{~min}$ samples. It has been proposed that the air must be removed from the autoclave chamber as sterilization capability has been proven only with saturated steam (1, 2). However, as shown here, the structure of DNA and amplifiable template could be eliminated by autoclaving even under encapsulation with air (i.e., without replacing the air with saturated steam).

\section{Effect of unsaturated steam}

Removal of template activity by autoclaving with encapsulation was further investigated using triplicate samples. A $10 \mu \mathrm{L}$ aliquot of the sample was autoclaved, followed by 10 -fold dilution with TE, and the $84 \mathrm{bp}$ fragment was then quantified. In two of three tubes containing encapsulated PCR product $\left[(8.27 \pm 0.34) \times 10^{11}\right.$ copies $/$ tube; determined by triplicate panels of the digital PCR assays] no amplification could be detected following autoclaving at $121^{\circ} \mathrm{C}$ 
for $40 \mathrm{~min}$, while one had $(1.74 \pm 0.13) \times$ $10^{4}$ copies/tube. More than $99.9999 \%$ of the template was considered to be removed by this treatment. Whereas amplifiable template appeared to be eliminated in the two samples, it is possible that the template DNA was present at quantities lower than the detection limit $(8.10$ copies/ $1 \mu \mathrm{L}$ sample). Longer autoclaving times or dilution of DNA solutions prior to treatment (less than $10^{8}$ copies $/ \mu \mathrm{L}$ or 1 ng DNA $/ \mu \mathrm{L}$ ) will be desirable for complete decontamination or management of the environment for sensitive applications.

Surprisingly, the efficiency of template removal was higher in the encapsulated samples than in the non-encapsulated ones. The triplicate samples without screw caps (where the air was replaced by steam as in the usual autoclaving) retained $(7.63 \pm 0.32) \times 10^{8},(2.11 \pm 0.02)$ $\times 10^{8}$, and $(8.24 \pm 0.02) \times 10^{8}$ copies/tube of template activity after autoclaving at $121^{\circ} \mathrm{C}$ for $40 \mathrm{~min}$. The key factor behind the high efficiency template removal in the samples encapsulated with air may be oxygen, since template activity was also protected by replacing air with pure nitrogen gas or reducing oxygen using an oxygen absorber (Ageless, Mitsubishi Gas Chemical Company Inc., Tokyo, Japan) prior to encapsulation.

Extended autoclaving for disposal of laboratory DNA waste

In order to determine the influence of solution composition, TE buffer and water samples were tested. Figure 2 shows a time course of the decline in template activity of autoclaved encapsulated and non-encapsulated samples in three different solutions. The samples exchanged with water (Figure 2A) and TE (Figure 2B) could be decontaminated much more easily, and the encapsulation methods were effective in all cases studied. Although the processing speed varied among the different conditions, removal of activity was completed in 80 min regardless of the solution composition and the presence or absence of encapsulation with air.

In conclusion, although we believe not autoclaving DNA waste is advisable for avoiding laboratory contamination, if autoclaving is unavoidable, it is better to encapsulate the waste in tightly capped tubes or bottles and to process at $121^{\circ} \mathrm{C}$ for $80 \mathrm{~min}$ (not $20 \mathrm{~min}$ ). Encapsulation with oxygen (air) seems favorable for quick removal of template activity. It would also be a good idea to develop a special steamer that does not exhaust steam and air, as this will help to minimize DNA contamination.
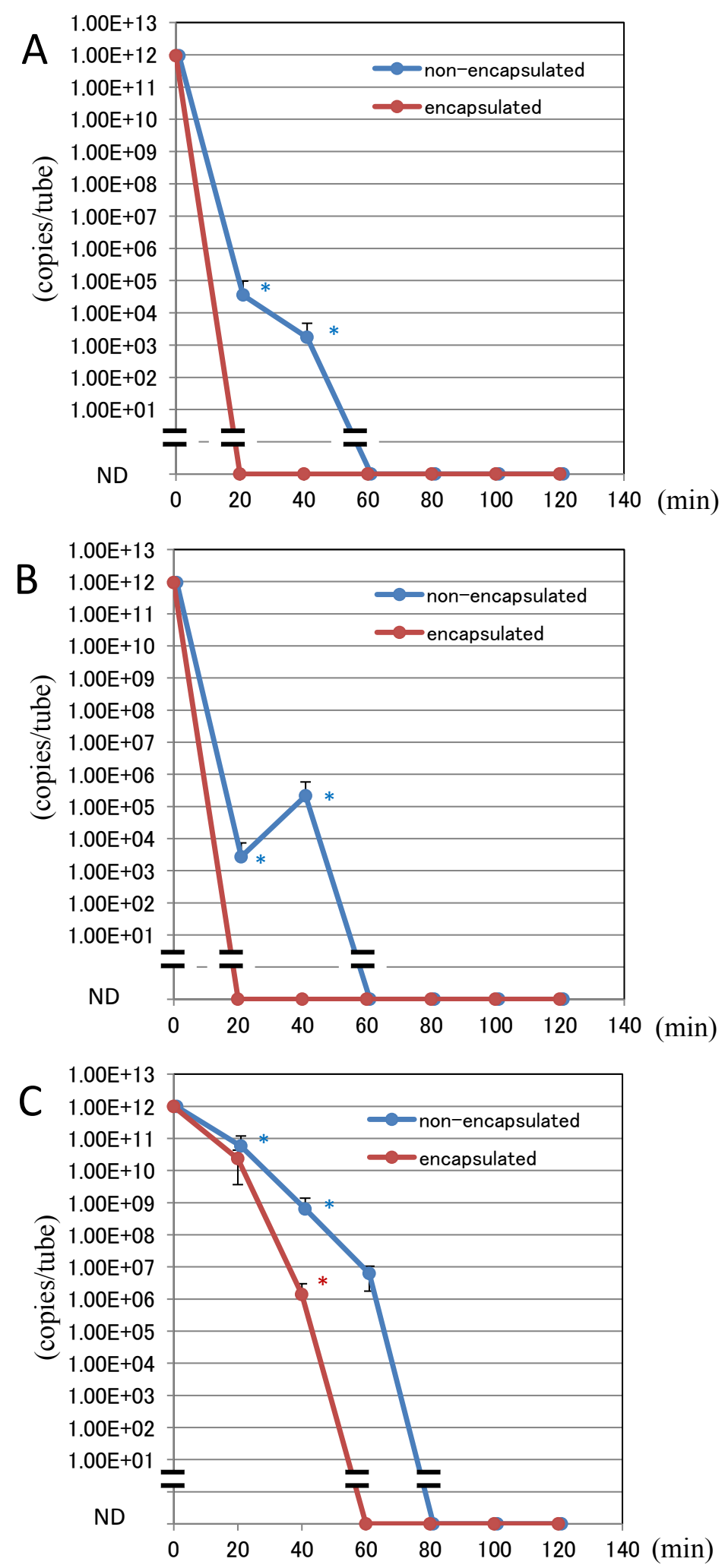

Figure 2. Template activity of DNA in the course of autoclaving. The template activities of a $84 \mathrm{bp}$ fragment of the $2682 \mathrm{bp} \mathrm{PCR} \mathrm{product} \mathrm{in} 10 \mu \mathrm{L}$ water (A), TE (B), and the crude PCR product (C) are indicated. Results for encapsulated and non-encapsulated samples are presented. X- and y-axes represent the length of the autoclave cycle at $121^{\circ} \mathrm{C}$ and the copy number of the template per tube, respectively. The samples that retained no PCR template activity were plotted at the level of ND (not detected). Error bars represent SD for three separate experimental samples. The error bars for plots of 0 min are less than $4 \%$ and are too small to be indicated. The plots with asterisks represent mean of values in different orders (SD is larger than mean) and the lower error bar could not be indicated in the logarithmic scale. 


\section{Author contributions}

MK proposed this project; TS conducted almost all of the experiments.

\section{Acknowledgments}

This work was performed at the Bio-measurement research group of Biomedical Research Institute at AIST. The authors wish to thank Yuji Sekiguchi (leader of the research group) and Masanao Oda (previous director of the Institute) for encouragement on conducting this work.

\section{Competing interests}

This work was performed at the Bio-measurement research group of Biomedical Research Institute at AIST. The authors wish to thank Yuji Sekiguchi (leader of the research group) and Masanao Oda (previous director of the Institute) for encouragement on conducting this work.

\section{References}

1. Hoyt, A., A.L. Chaney, and K. Cavell. 1938. Studies on steam sterilization and the effects of air in the autoclave. J. Bacteriol. 36:639-652.
2. Lee, C.-H., T.J. Montville, and A.J. Sinskey. 1979. Comparison of the efficiency of steam sterilization indicators. Appl. Environ. Microbiol. 37:113-117.

3. Porter-Jordan, K., E.I. Rosenberg, J.F. Keiser, J.D. Gross, A.M. Ross, S. Nasim, and C.T. Garrett. 1990. Nested polymerase chain reaction assay for the detection of cytomegalovirus overcomes false positives caused by contamination with fragmented DNA. J. Med. Virol. 30:85-91.

4. Dwyer, D.E. and N. Saksena. 1992. Failure of ultra-violet irradiation and autoclaving to eliminate PCR contamination. Mol. Cell. Probes 6:87-88.

5. Shen, H., S. Rogelj, and T.L. Kieft. 2006. Sensitive, real-time PCR detects low-levels of contamination by Legionella pneumophila in commercial reagents. Mol. Cell. Probes 20:147-153.

6. Singh, C.K., A. Ojha, R.K. Bhatanagar, and D.N. Kachru. 2008. Detection and characterization of recombinant DNA expressing vip3A-type insecticidal gene in GMOs--standard single, multiplex and construct-specific PCR assays. Anal. Bioanal. Chem. 390:377-387.

7. Gefrides, L.A., M.C. Powell, M.A. Donley, and R. Kahn. 2010. UV irradiation and autoclave treatment for elimination of contaminating DNA from laboratory consumables. Forensic Sci. Int. Genet. 4:89-94.

8. Yap, J.M., C.E. Goldsmith, and J.E. Moore. 2013. Integrity of bacterial genomic DNA after autoclaving: possible implications for horizontal gene transfer and clinical waste management. J. Hosp. Infect. 83:247-249.

9. Hoshina, S. 2000. Measures for the disposal of non-regulated alternative medical wastes-Cloned DNA of amplified DNA as waste materials. in Japanese. Rinsho Byori Suppl 112:98-103.

10. Champlot, S., C. Berthelot, M. Pruvost, E.A. Bennett, T. Grange, and E.-M. Geigl. 2010. An efficient multistrategy DNA decontamination procedure of PCR reagents for hypersensitive PCR applications. PLoS ONE 5:e13042.

11. Espy, M.J., T.F. Smith, and D.H. Persing. 1993. Dependence of polymerase chain reaction product inactivation protocols on amplicon length and sequence composition. J. Clin. Microbiol. 31:2361-2365.

Received 26 June 2013; accepted 04 November 2013.

Address correspondence to Tetsushi Suyama, National Institute of Advanced Industrial Science and Technology (AIST), Tsukuba, Ibaraki, Japan. E-mail: t.suyama@aist.go.jp

To purchase reprints of this article, contact: biotechniques@fosterprinting.com

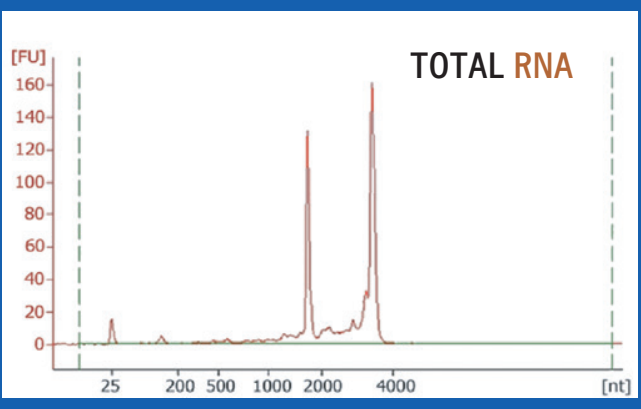

The single-step method without phase separation

No DNase treatment necessary

$\checkmark$ RNA ready for RT-PCR, microarrays and other applications

No need for refrigerated centrifuge

$\checkmark$ One reagent for solid and liquid samples

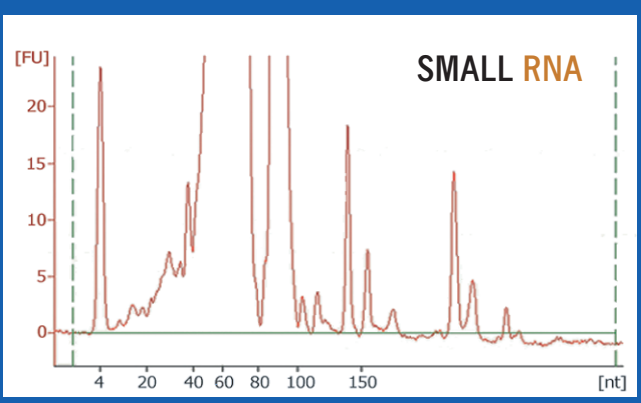

